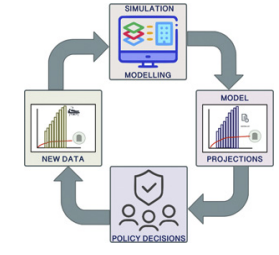

\section{WICKED PROBLEMS \\ AND \\ PROPORTIONALITY: IS \\ THE LESSER OF TWO \\ EVILS THE BEST WE \\ CAN DO?}

\section{To the Editor:}

We read with great interest the commentary by Dr Rajagopal on priority setting and decision-making during the Coronavirus Disease 2019 (COVID-19) pandemic as they pertain to the reduction in cardiovascular surgical procedures in anticipation for a surge in the COVID-19 pandemic. ${ }^{1}$ The question from his commentary is an important one: If cardiac surgery is lifesaving, how do we prioritize scarce critical care resources such as ventilators and intensive care unit beds?

What Dr Rajagopal describes is a "wicked" problem, not in the sense that the problem is evil but in that the problem is highly complex, a term derived from social policy studies. ${ }^{2}$ In contrast to "tame" problems, wicked problems can be difficult to define, because the problems are commonly rife with competing goals and values. Furthermore, there are no simple solutions or "easy fixes" to wicked problems; proposed solutions are usually characterized as "good enough." In fact, any possible solution may unleash a fury of new problems or concerns. These characteristics of wicked problems aptly describe our current conundrum of how to manage patients with cardiac disease during the COVID-19 pandemic in the setting of resource constraints.

Resource allocation decisions can be made on principles of distributive justice or procedural justice. Prominent frameworks in distributive justice include utilitarianism, egalitarianism, and communitarianism. ${ }^{3}$ Undoubtedly, cardiac surgery improves life expectancy for patients with severe cardiovascular disease, and thus its prioritization can be justified on utilitarian principles. However, the shifting away of resources from cardiac surgical patients to treat critically ill patients with COVID-19 helps limit disease transmissions and may be justified on communitarian principles. Furthermore, although our surgeries are lifesaving, we note that some elective patients may potentially tolerate a modest delay. However, such delays may not pass without a price. For example, patients awaiting coronary artery bypass surgery are at risk of

\footnotetext{
The Editor welcomes submissions for possible publication in the Letters to the Editor section that consist of commentary on an article published in the Journal or other relevant issues. Authors should: • Include no more than 500 words of text, three authors, and five references. • Type with double-spacing. • See http://jtcs.ctsnetjournals.org/ misc/ifora.shtml for detailed submission instructions. • Submit the letter electronically via jtcvs.editorialmanager.com. Letters commenting on an article published in the JTCVS will be considered if they are received within 6 weeks of the time the article was published. Authors of the article being commented on will be given an opportunity of offer a timely response ( 2 weeks) to the letter. Authors of letters will be notified that the letter has been received. Unpublished letters cannot be returned.
}

developing complications during the wait-time period. Head and colleagues ${ }^{4}$ reported a rate of death and nonfatal myocardial infarction at $1.1 \%$ and $1 \%$ per 1000 patient-weeks, respectively, when awaiting surgery. ${ }^{4}$ This highlights the important concept of proportionality, where decided actions should be proportional to the good that can be accomplished and the inevitable resulting harm. ${ }^{5}$

Overall, we have the daunting task of caring for the cardiac surgical patient in front of us in the midst of a deadly and rapidly evolving public health crisis that impacts society. To begin to tackle this difficult problem, our decisions must be made on the best available data and evidence in a transparent manner. When reasonable disagreement exists, the principles of distributive justice such as utilitarianism and communitarianism may not be enough to placate all stakeholders, and we must rely instead on procedural justice. ${ }^{6}$ Procedural justice may take several forms but typically involve the use of decision tools and processes to justify the distribution of constrained resources after accounting for competing stakeholder interests. ${ }^{7}$ The use of decision analytic modeling can be a useful tool to help synthesize available evidence to model the envelope of possible scenarios and help inform critical resource decisions during a pandemic. ${ }^{8}$ Rapid iteration of these models with real-time data may help efficiently allocate resources to COVID-19 or cardiac surgical patients depending on the prevailing COVID-19 incidence rates in that jurisdiction. ${ }^{9}$ In Ontario, Canada, such a model was used to estimate both COVID-19-related deaths versus cardiac procedure waitlist death and help informed decisions around halting and resuming elective cardiac procedures based on the evolving COVID-19 transmission epidemiology. These models help ensure that when we invoke principles such as proportionality, which may be a detriment to cardiac surgical patients, the most urgent cardiac cases can continue to be treated while resources are dedicated to those with COVID-19. Although there may be no perfect answers, we must use all tools available to find solutions that are at the least acceptable to stakeholders.

Ahmad Makhdoum, MD, MSc Derrick Y. Tam, $M D, P h D$ Stephen E. Fremes, MD, MSc Division of Cardiac Surgery Schulich Heart Centre Department of Surgery Sunnybrook Health Sciences Centre University of Toronto Toronto, Ontario, Canada

\footnotetext{
References

1. Rajagopal K. Commentary: Implications of coronavirus disease 2019 (COVID-19) for cardiac surgery: priorities and decisions. J Thorac Cardiovasc Surg. 2020;160:951-2.
} 
The authors reported no conflicts of interest.

The Journal policy requires editors and reviewers to disclose conflicts of interest and to decline handling or reviewing manuscripts for which they may have a conflict of interest. The editors and reviewers of this article have no conflicts of interest.

2. Rittel HWJ, Webber MM. Dilemmas in a general theory of planning. Policy Sci. 1973;4:155-69.

3. Drake D, Morrow CD, Kinlaw K, De Bonis M, Zangrillo A, Sade RM Cardiothoracic surgeons in pandemics: ethical considerations. Ann Thorac Surg. 2020;160:456-9.

4. Head SJ, da Costa BR, Beumer B, Stefanini GG, Alfonso F, Clemmensen PM, et al. Adverse events while awaiting myocardial revascularization: a systematic review and meta-analysis. Eur J Cardiothorac Surg. 2017;52:206-17.

5. Hermerén G. The principle of proportionality revisited: interpretations and applications. Med Health Care Philos. 2012;15:373-82.

6. Tam DY, Wijeysundera HC, Fremes SE. Outcomes matter but processes may matter more in valve procurement. J Thorac Cardiovasc Surg. 2019;157:e201-2.

7. Daniels N, Sabin JE. Accountability for reasonableness: an update. BMJ. 2008; 337:a1850.

8. Tam DY, Naimark D, Natarajan MK, Woodward G, Oakes G, Rahal M, et al. The use of decision modelling to inform timely policy decisions on cardiac resource capacity during the COVID-19 pandemic. Can J Cardiol. 2020;36:1308-12.

9. Barrett K, Khan YA, Mac S, Ximenes R, Naimark DMJ, Sander B. Estimation of COVID-19-induced depletion of hospital resources in Ontario, Canada. CMAJ. 2020;192:E640-6

https://doi.org/10.1016/j.jtcvs.2020.06.128

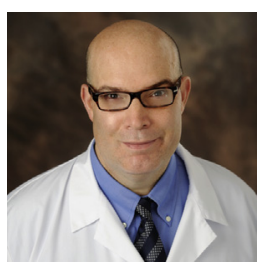

REPLY: ELECTIVE WITH AN ASTERISK Reply to the Editor:

\begin{abstract}
"In preparing for battle I have always found that plans are useless, but planning is indispensable."
\end{abstract}

—Dwight D. Eisenhower

I read with interest the response from Mahkdoum and colleagues $^{1}$ to Rajagopal ${ }^{2}$ positing a wicked dilemma for cardiac surgeons. Although cardiac surgery clearly saves lives, George and colleagues ${ }^{3}$ distilled a hard lesson from their coronavirus disease 2019 (COVID-19) pandemic experience in New York during which they triaged cardiac surgery patients to keep procedures to a minimum and reallocate personnel and resources to treat COVID-19 patients to save more lives. Rajagopal took 1 provocative step further: If we take the global perspective, cardiac surgery patients are not special, nor should they have special consideration during a pandemic. Although some cardiac surgery is time imperative and lifesaving, most procedures are life improving or the best treatment for a given population/disease. Mahkdoum and colleagues ${ }^{1}$ outline an ethical and societal framework in answer to this dilemma. The essay is thoughtful, thorough, and compelling. They marry cardiac surgeons' concerns with those of the ethicists, ${ }^{4}$ adding modeling and simulation to the loop to enable better decisions, more efficiently allocate resources, and build stakeholder consensus. Why not?

Currently in Florida, health care has critical shortages. As I write, I am struggling to find a bed for a 26-year-old woman with COVID-19 acute respiratory disease syndrome who was pregnant until earlier today and critically hypoxic on venoarterial extracorporeal membrane oxygenation (ECMO) at a hospital 200 miles away. Bad weather is blocking air transport. Local institutions have declined transfer due to capacity. We are at capacity. Should we take a patient who needs our expertise from outside our service area while we are at capacity? What implications does this decision have for subsequent requests? Who should decide? Who are the stakeholders for this patient? For the patients who will need ECMO tomorrow? What do the models say? Our analytics predict growing shortfalls in beds, staff, and medicines.

Clear need exists to model the pandemic and simulate resource needs. Surgeon-scientists seek data to measure, improve, and predict. All health care institutions participated in some predictive modeling. Despite ample data and complex modeling, most models performed poorly. Why? Models cannot consider irrational behavior, assuming instead that people will act in their best interest, such as to minimize exposure to the pathogen during a pandemic - an assumption that may be true in Toronto but apparently does not hold in Florida. ${ }^{5}$ Models do not include variability in hospital behavior. During a statewide halt of elective surgery, some hospitals continued to perform these procedures, nuancing the definition of elective in the context of local COVID-19 burden. Such nuances exist within a hospital. My colleagues suggested that transcatheter aortic valve replacement is elective with an asterisk, invoking, as Mahkdoum and colleagues ${ }^{1}$ did, the price of waiting. These patients consume little in the way of resources. Elective with an asterisk. Heart transplant? Ventricular assist device placement? How do we weigh the needs of 1 life against the needs of another?

Models need reliable data. Data such as disease incidence, case fatality rate, and risk of transmission are essential to even the most basic modeling. These models depend on public data from broad testing for COVID-19, without which, modeling is marginal at best. This pandemic has unmasked our vulnerability to our data or lack thereof.

Capacity only exists for a moment in time with the space, resources, and team to care for a given patient. Despite broadcasting to the Florida ECMO Network and placing calls to friends and colleagues, no center accepted the patient I described earlier. Despite our hospital being at capacity, our ECMO transport team brought her via 